2007;13(8):952-961.

11. Osterreicher $\mathrm{CH}$, et al. Fibroblast-specific protein 1 identifies an inflammatory subpopulation of macrophages in the liver. Proc Natl Acad Sci U S A. 2011; 108(1):308-313.

12. Kong P, Christia P, Saxena A, Su Y, Frangogiannis NG. Lack of specificity of fibroblast-specific protein 1 in cardiac remodeling and fibrosis. Am J Physiol Heart Circ Physiol. 2013;305(9):H1363-H1372.

13. Eisenberg LM, Markwald RR. Molecular regulation of atrioventricular valvuloseptal morphogenesis. Circ Res. 1995;77(1):1-6
14. Shinde AV, Frangogiannis NG. Fibroblasts in myocardial infarction: A role in inflammation and repair. J Mol Cell Cardiol. 2014;70C:74-82.

15. Braitsch CM, Kanisicak O, van Berlo JH, Molkentin JD, Yutzey KE. Differential expression of embryonic epicardial progenitor markers and localization of cardiac fibrosis in adult ischemic injury and hypertensive heart disease. J Mol Cell Cardiol. 2013; 65:108-119.

16. Hinz B. The myofibroblast: paradigm for a mechanically active cell. J Biomech. 2010;43(1):146-155.

17. Souders CA, Borg TK, Banerjee I, Baudino TA. Pres- sure overload induces early morphological changes in the heart. Am J Pathol. 2012;181(4):1226-1235.

18. Zhu H, Fan GC. Role of microRNAs in the reperfused myocardium towards post-infarct remodelling. Cardiovasc Res. 2012;94(2):284-292

19. Hasenfuss G. Animal models of human cardiovascular disease, heart failure and hypertrophy. Cardiovasc Res. 1998;39(1):60-76.

20. Masci PG, et al. Incremental prognostic value of myocardial fibrosis in patients with non-ischemic cardiomyopathy without congestive heart failure. Circ Heart Fail. 2014;7(3):448-456.

\title{
Fatness and fertility: which direction?
}

\author{
Stephanie B. Seminara \\ Harvard Reproductive Sciences Center and Reproductive Endocrine Unit, Department of Medicine, \\ Massachusetts General Hospital, Boston, Massachusetts, USA.
}

\begin{abstract}
Metabolic status has long been thought to determine reproductive status, with abnormal metabolic phenotypes altering reproductive cascades, such as the onset of puberty. In this issue of the JCI, Tolson and colleagues provide evidence that kisspeptin, a hormone that promotes sexual maturation, regulates metabolism. Female mice lacking the kisspeptin receptor (KISS1R) gained more weight than control animals, and this weight gain was caused not by increased food consumption, but by an overall decrease in energy and metabolism. While this study provides a direct link between the kisspeptin pathway and metabolic output, more work will need to be done to determine whether alterations in this pathway contribute to human obesity.
\end{abstract}

\section{Leptin and kisspeptin: linking metabolism and reproduction?}

The concept that a minimum weight-toheight ratio is necessary for the onset and maintenance of menstrual cycles was first introduced in the 1970s; however, uncovering the physiologic pathways that connect reproduction and metabolism has been challenging $(1,2)$. In the 1990 s, the discovery that patients deficient for leptin (a cell-signaling hormone critical for weight regulation) or leptin signaling have abnormal pubertal development led many to hail leptin as the long-sought link between energy stores and reproductive function $(3,4)$. Then in 2003, inactivating mutations in the gene encoding the kisspeptin receptor (KISS1R) were found to promote hypogonadotropic hypogonadism in mice and humans, catapulting the kisspeptin signaling pathway into the spotlight as a critical stimulus for activating gonadotropinreleasing hormone $(\mathrm{GnRH})$ secretion and initiation of the hypothalamic-pituitarygonadal cascade $(5,6)$. Through numer-

Conflict of interest: The author has declared that no conflict of interest exists.

Citation for this article: J Clin Invest. 2014, 124(7):2853-2854. doi:10.1172/JCI76623. ous neuroanatomic, electrophysiologic, pharmacologic, and genetic studies, the kisspeptin system was proven to be a key element in reproductive maturation and function. Soon after the discovery of kisspeptin's role in regulating reproduction, investigators began to explore the possibility of a link between energy status and the kisspeptin system. States of negative energy balance, such as food deprivation, were found to induce suppression of the hypothalamic kisspeptin system, while administration of kisspeptin ameliorated the reproductive failure associated with undernutrition (7). Furthermore, leptin administration to leptin-deficient mice increased kisspeptin expression (8); therefore, momentum grew for the hypothesis that nutritional signals, such as leptin, acted through kisspeptin-expressing neurons to determine the timing of sexual maturation.

Enthusiasm for the hypothesis that leptin and kisspeptin coordinate the onset of sexual maturation dampened in 2011 following a report that selective deletion of leptin receptors from kisspeptin-expressing neurons did not affect sexual maturation and fertility (9). This surprising finding suggested that direct leptin action on kisspeptin neurons is not required for puberty onset in mice; however, this study did not eliminate that possibility that leptindependent effects on reproduction are indirectly transmitted through kisspeptinexpressing neurons, potentially adding layers of complexity to the regulation of these hypothalamic networks.

\section{Metabolic status determines reproduction - or does it?}

As work on the relationship between metabolism and kisspeptin progressed, it appeared that the directional arrow in this association begins with the metabolic status of the organism (i.e., undernutrition, overnutrition, or lactation), which then leads to abnormal phenotypes in the reproductive cascade (delayed puberty or infertility). In this issue of the JCI, Tolson et al. have turned this paradigm on its head and present data suggesting that perturbations in kisspeptin signaling affect metabolism (10). Female, but not male, mice lacking KISS1R weighed significantly more than control animals. Furthermore, Kiss1 $r^{-1-}$ females had increased fat mass, hyperleptinemia, higher fasting glucose, and impaired glucose tolerance in the setting of reduced metabolism and energy expenditure. Moreover, ovariectomized KISS1R-deficient females weighed more than ovariectomized controls, which suggests that the obesity phenotype is independent of differences in gonadal steroids due to loss of kisspeptin signaling.

Notably, weight differences between Kiss $1 r^{-/-}$females and control animals began to emerge at eight to ten weeks of age and continued to increase out to 18 weeks (10). Unfortunately, there are 
almost no previously published data on the body weight of mice lacking kisspeptin or KISS1R well into adulthood. A previous study reported that female mice lacking kisspeptin-expressing cells had weights at eight weeks that were comparable to the weights reported by Tolson and colleagues; however, this group did not extend their measurements beyond the eight-week timepoint (11). In another study, female kisspeptin-knockout mice were reported to be significantly smaller than their female littermates at two months of age (12), while a third group observed a decrease in weight of Kiss1r-/- males compared with WT and heterozygous littermates at nine weeks, but no decrease or noticeable difference in Kiss $1 r^{-/-}$females (13). During our laboratory's initial characterization of Kiss $1^{-/-}$and Kiss $1 r^{-1}$ mice that we generated by introducing ES cells from 129/S embryos into C57BL/ 6 blastocysts, crossing chimeras with 129/S1/SvImJ females, and interbreeding the heterozygotes to generate knockouts, we did not extend weight measurements past nine to 12 weeks (14). There was no overt difference in the weight of these female mice. The mice used by Tolson et al. were created on a mixed C57BL/ 6 $\times 129 / \mathrm{S} 1 / \mathrm{SvImJ}$ background (10); therefore, continued exploration of metabolic consequences of perturbations in the kisspeptin signaling pathway will require studies using multiple strains of both male and female Kiss $1^{-/-}$and Kiss1r- ${ }^{--}$mice to further dissect the contributions of strain, gender, method of creation, and dependency on kisspeptin signaling (ligand vs. receptor) in this relationship.

\section{Conclusions and future directions}

While the revelation by Tolson and colleagues that disrupted kisspeptin signaling promotes murine metabolic dysfunction is exciting, it is unclear whether this weight phenotype is relevant to humans. Unfortunately, very few patients with terminating mutations of the genes encoding either kisspeptin or its receptor have been identified and described in the literature. Although these few individuals were evaluated at various ages, metabolic phenotypes were not reported; it is assumed that overt obesity would have been noted, but this phenotype was not commented upon $(5,15)$. Certainly, the need to phenotype animal models over time is an increasingly important theme in kisspeptin-neurokinin B-dynorphin biology. An important lesson emerging from these studies is that the reproductive phenotypes of both humans and mice bearing mutations and/ or deletions in the kisspeptin pathway are not always static. For example, Kiss $1^{-/-}$and Kiss $1 r^{--}$mutant mice have a dynamic phenotype characterized by persistent GnRH activity, which becomes more apparent over time (16). Reproductive maturation can occur in the absence of kisspeptin signaling prior to certain windows in development, presumably due to the emergence of compensatory pathways (11). In line with these observations, humans with mutations in the neurokinin B signaling pathway present with hypogonadotropism at a young age, but have shown a reversal of this phenotype as adults $(17,18)$. Thus, the greater the phenotypic armamentarium used to study sexual maturation and fertility, the greater the phenotypic complexity that may emerge.

On a final point, interactions between metabolic cues and kisspeptin signaling, regardless of directionality, have largely been envisioned as taking place within hypothalamic networks. Little attention to the role of kisspeptin in the periphery has been paid until recently, when a hormonal circuit linking hyperglucagonemia, hepatic kisspeptin secretion, and impaired insulin secretion was uncovered (19). Interestingly, in that circuit, kisspeptin production, specifically in the liver, inhibited glucose-dependent insulin secretion, which suggests that impaired kisspeptin signaling might actually stimulate insulin secretion - a finding not observed by Tolson et al. (10). Thus, kisspeptin's role in metabolic circuitry may be unique and differentially influential in different tissues.

The interrelationship between reproduction and metabolism continues to intrigue investigators and clinicians alike. Studies able to dissect its directionality, compensatory pathophysiology, underlying genetic signatures, and central versus peripheral inputs will be required to solve its complexity.

\section{Acknowledgments}

S.B. Seminara is supported by grants K24 HD067388, R01 HD043341, and U54 HD028138 from the Eunice K. Shriver National Institute for Child Health and Human Development (NICHD).

Address correspondence to: Stephanie B. Seminara, Massachusetts General Hospital, Reproductive Endocrinology, BHX 504, 55 Fruit St., Boston, Massachusetts
02114, USA. Phone: 617.724.8304; Fax: 617.726.5357; E-mail: SSEMINARA@mgh. harvard.edu.

1. Kennedy GC, Mitra J. Body weight and food intake as initiating factors for puberty in the rat.J Physiol. 1963; 166:408-418.

2. Frisch RE, McArthur JW. Menstrual cycles: fatness as a determinant of minimum weight for height necessary for their maintenance or onset. Science. 1974; 185(4155):949-951.

3. Clément $\mathrm{K}$, et al. A mutation in the human leptin receptor gene causes obesity and pituitary dysfunction. Nature. 1998;392(6674):398-401.

4. Montague CT, et al. Congenital leptin deficiency is associated with severe early-onset obesity in humans. Nature. 1997;387(6636):903-908.

5. de Roux N, Genin E, Carel JC, Matsuda F, Chaussain JL, Milgrom E. Hypogonadotropic hypogonadism due to loss of function of the KiSS1derived peptide receptor GPR54. Proc Natl Acad Sci U S A. 2003;100(19):10972-10976.

6. Seminara SB, et al. The GPR54 gene as a regulator of puberty. N Engl J Med. 2003;349(17):1614-1627.

7. Castellano JM, et al. Changes in hypothalamic KiSS-1 system and restoration of pubertal activation of the reproductive axis by kisspeptin in undernutrition. Endocrinology. 2005; 146(9):3917-3925.

8. Smith JT, Acohido BV, Clifton DK, Steiner RA. KiSS-1 neurones are direct targets for leptin in the ob/ob mouse. J Neuroendocrinol. 2006; 18(4):298-303.

9. Donato J Jr, et al. Leptin's effect on puberty in mice is relayed by the ventral premammillary nucleus and does not require signaling in Kiss 1 neurons. J Clin Invest. 2011;121(1):355-368.

10. Tolson KP, et al. Impaired kisspeptin signaling decreases metabolism and promotes glucose intolerance and obesity. J Clin Invest. 2014; 124(7):3075-3079.

11. Mayer C, Boehm U. Female reproductive maturation in the absence of kisspeptin/GPR54 signaling. Nat Neurosci. 2011;14(6):704-710.

12. d'Anglemont de Tassigny $X$, et al. Hypogonadotropic hypogonadism in mice lacking a functional Kiss1 gene. Proc Natl Acad Sci U S A. 2007; 104(25):10714-10719.

13. García-Galiano, D et al. Kisspeptin signaling is indispensable for neurokinin B, but not glutamate, stimulation of gonadotropin secretion in mice. Endocrinology. 2012;153(1):316-328.

14. Lapatto R, et al. Kiss1-/- mice exhibit more variable hypogonadism than Gpr54-/- mice. Endocrinology. 2007;148(10):4927-4936.

15. Bo-Abbas Y, Acierno JS Jr, Shagoury JK, Crowley WF Jr, Seminara SB. Autosomal recessive idiopathic hypogonadotropic hypogonadism: genetic analysis excludes mutations in the gonadotropin-releasing hormone $(\mathrm{GnRH})$ and $\mathrm{GnRH}$ receptor genes. J Clin Endocrinol Metab. 2003;88(6):2730-2737.

16. Chan YM, Broder-Fingert S, Wong KM, Seminara SB. Kisspeptin/Gpr54-independent gonadotrophin-releasing hormone activity in Kiss 1 and Gpr54 mutant mice. J Neuroendocrinol. 2009; 21(12):1015-1023.

17. Gianetti E, et al. TAC3/TACR3 mutations reveal preferential activation of gonadotropin-releasing hormone release by neurokinin B in neonatal life followed by reversal in adulthood. J Clin Endocrinol Metab. 2010;95(6):2857-2867.

18. Sidhoum VF, et al. Reversal and relapse of hypogonadotropic hypogonadism: resilience and fragility of the reproductive neuroendocrine system. J Clin Endocrinol Metab. 2014;99(3):861-870.

19 . Song WJ, et al. Glucagon regulates hepatic kisspeptin to impair insulin secretion. Cell Metab. 2014;19(4):667-681. 